


\section{Don't you know that you want to trust me? Subliminal goal priming and persuasion}

Jean-Baptiste Légal, Julien Chappé, Viviane Coiffard, Audrey Villard-Forest

"Watching T.V. I start to cry; For no reason I don't know why; Could it be from messages on my TV; Which I'm getting subliminally" (Muir, 1993).

Can subliminal exposure lead people to adopt an idea, an attitude, or an action? In other words, is subliminal persuasion a myth or a fact?Subliminal influence has been a recurrent topic of debate in both scientific and popular communities since Vicary (in a press conference held in 1957) claimed (even if he finally admitted it was a hoax) that subliminal exposure to short sentences, such as "Drink coke" or "Eat pop-corn", could drastically influence people's will to consume that products. To date, evidence suggests that subliminal exposure to faces, words, or brands, can to some extent influence judgments about people (e.g., Bargh \& Pietromonaco, 1982), judgments about ads (Channouf, 2000), people's self-evaluation (e.g., Baldwin, Carrel, \& Lopez, 1990), their attitudes (e.g., Zajonc, 1980), and even their behavior (Brasel \& Gips, 2011).

Subliminal exposure has also been used to prime goals, directly or through goal-related constructs (e.g., Chartrand \& Bargh, 1996; for evidence about nonconscious goal-priming and pursuit, see also Bargh, Gollwitzer, Lee-Chai, Barndollar, \& Trötschel, 2001; Custers \& Aarts, 2010). In the framework of persuasion, goal-priming research has essentially focused on need-related behaviors (e.g., thirst, hunger). For instance, Cooper and Cooper (2002) subliminally activated a motiva-tional state of thirst using stimuli related to thirst (the word "thirsty", pictures of Coca Cola ${ }^{\circledR}$ cans, or picture of a sweating boxer) embedded in an episode of The Simpsons. Compared to a control condition, par-ticipants' ratings of thirst were significantly higher following the

is We would like to thank Dominique Muller, Fabrice Gabarrot, Clémentine Bry, and Daniel Priolo for their helpful comments on an earlier version of this paper. priming manipulation. Strahan, Spencer, and Zanna (2002) also suggested that a message could be perceived as more persuasive when it corresponds to an active motive or need. Thus, for already thirsty participants, a relevant ad (i.e., a message about a thirstquenching beverage) could be more convincing if it was accompanied by the subliminal presentation of thirst-related words. In the same line, Karremans, Stroebe, and Claus (2006) primed participants with the brand of a drink (Lipton Ice). They demonstrated that subliminal priming of a goal-related feature (i.e., the brand of the drink: Lipton Ice) affected participants' choice, as well as their intention to drink the primed brand, but only if they were thirsty.

In a way, research about subliminal persuasion only partially benefitted from findings concerning nonconscious goal pursuit Indeed, in previous research, participants were not primed with goals directly related to features typically associated with source effects (i.e., effects produced by characteristics associated to the source of the message and that influence persuasion, such as credibility, ex-pertise, and attractiveness; see Petty \& Wegener, 1998), but with means to accomplish the goal (Karremans et al., 2006) or goal-related concept (Cooper \& Cooper, 2002; Strahan et al., 2002; see also Dijksterhuis, Wegner, \& Aarts, 2001; cited in Dijksterhuis, Aarts, \& Smith, 2005). In our research, we tried to use goal priming to enhance the persuasiveness of a message in a more direct way. Specifically, we attempted to use the goal "to trust" to influence participants' evaluation of the message and its source.

Previous studies have found that priming general goals could influence behavior and cognitive processing. For instance, Chartrand and Bargh (1996) demonstrated that a general impression formation goal could be primed; Albarracin et al. (2008) also demonstrated that activating general action or inaction goals influenced behavioral outcome (doodling on a piece of paper) as well as cognitive outcomes (recall performance; problem solving). In our view, the goal "to trust" is one of these general or high order goals. Indeed, it has been proposed (e.g., Fiske \& Taylor, 2008) that motivation to trust other people 
is one of our most basic motivations, as people generally expect good things from other people. This inclination to trust other people would render "to trust" a rather accessible and easily activated goal.

In this study, we tried to determine whether priming the goal "to trust" could influence the way a persuasive message is processed and its influence on judgment and behavioral intentions. We hypothesized that goal-priming would lead to a better acceptance of a persuasive message, a more positive perception of the source of the message, as well as greater intentions to behave in accordance with the message.

\section{Method}

\section{Participants and design}

Ninety-three undergraduate psychology students (80 women and 13 men) participated in this study in exchange for course credits. Participants were randomly assigned to one of the two conditions: goal priming or control.

\section{Procedure and material}

We chose to use a persuasive message promoting the benefits of drinking tap water, which is a simple, an easy-to-do, and a practical daily pro-environmental behavior. Before the experimental session, participants received a questionnaire designed to assess their initial attitudes toward tap water. Participants had to indicate, on a six points Likert scale, their degree of agreement with the following statements: "I like tap water", "I think that tap water tastes bad" (reversed score), and "I think that tap-water is good for health". We computed a global score of attitude toward tap water (Cronbach's $\alpha=0.89$ ). Attitude scores ranged from 1 to $6, M=3.88$, and $S D=1.87$.

Upon arriving to the lab, participants were informed that they would participate in two independent studies. They were then invited to start with the study on visual attention. The visual detection task they performed was actually a pretext to carry out the subliminal goal priming. Indeed, during the task in which participants had to indicate which shape ("O" or " $\mathrm{X}$ " displayed during $120 \mathrm{~ms}$ ) they perceived on the computer screen, they were subliminally primed $(30 \mathrm{~ms})$ with "to trust" or with verbs ${ }^{1}$ closely related to this goal (e.g., to approve, to accept, to agree). Primes were flashed in the center of the screen and were immediately followed by a mask, which was displayed until participants responded. Thirty primes were flashed, half of them directly related to the goal "to trust". Participants in the control condition also performed the task; however, they were not exposed to subliminal primes. In order to check the subliminal character of our priming manipulation, a separate group of 23 participants received the task with specific instructions. They were informed that words would flash during the visual detection task and that they would have to detect these words and to report them at the end of the task. None of the participants were able to recall any word flashed during the subliminal priming manipulation, indicating that the stimuli were displayed beneath the subjective threshold.

Once the visual detection task was completed, participants were told the first study was over and that they would now complete a survey about water consumption. They were first given $80 \mathrm{~s}$ to read a persuasive message promoting tap-water consumption. The message was illustrated with the picture a woman, Mrs. Marie, presented as the executive head of the regional water control organization. Subsequently, participants answered questions about the message they read (agreement, clarity), the source of the message (likeable/nice, trustworthy, competent), and behavioral intentions about tap water (drinking more tap water; not buying bottled water). In the last part, a funneled questionnaire allowed

\footnotetext{
${ }^{1}$ Verbs in French are single words.
}

us to assure that participants had not perceived subliminal primes and did not discovered the relation between the two studies.

\section{Results}

In order to control for the potential effect of participants' attitudes, ANCOVAs were used to analyze the data. Initial attitude about tap water consumption was used as a covariate. Table 1 summarizes the means, means adjusted for the covariate and standard deviations for all variables.

\section{Message}

Data analysis yielded an effect of the priming manipulation on message assessment, $F(1,90)=4.66, p<0.05, \eta^{2}=0.04$. Participants primed with the goal of trusting displayed a greater agreement with the message's arguments compared to the participants in the control condition $(M=4.62$ and $M=4.18$, respectively). Attitude about tapwater was a significant covariate for this measure, $F(1,90)=48.77, p$ $<001$. We found no differences in the evaluation of the message's clarity.

\section{Source of the message}

Goal priming influenced judgments about Mrs. Marie, who delivered the pro-tap water message. Particularly, compared to control participants, primed participants perceived Mrs. Marie as more likeable/nice, $F(1,90)=3.73, p<0.05, \eta^{2}=0.04(M=4.49$ and $M=4.26)$ and more trustworthy, $F(1,90)=5.78, p<0.02, \eta^{2}=0.06$ $(M=4.02$ and $M=3.35)$. The covariate contributed significantly to the perception of the source as being likeable, $F(1,90)=4.63, p<0.05$, and trustworthy, $F(1,90)=5.12, p<0.03$. No effect was found for perceived competency.

\section{Behavioral intentions}

Goal priming had an effect on behavioral intentions about water consumption. Participants primed with the goal of trusting and exposed to the pro tap-water message indicated that they would drink more tap water, $F(1,90)=5.24, p=0.02, \eta^{2}=0.06(M=3.74$ and $M=2.82$ ) and avoid buying bottled water, $F(1,90)=9.98, p=$ $0.002, \eta^{2}=0.10(M=2.70$ and $M=1.73$; reversed scores). The covariate, attitude about tap water, was significantly related to both intentions with $p<0.001$.

Table 1

Judgment of the message, judgment of the source, and behavioral intentions as a function of priming condition.

\begin{tabular}{llllll}
\hline Priming condition & \multicolumn{2}{l}{ Control } & & \multicolumn{2}{l}{ Trust } \\
\cline { 2 - 3 } & $M\left(M_{\text {Adj. }}\right)$ & $S D$ & & $M\left(M_{\text {Adj. }}\right)$ & $S D$ \\
\hline $\begin{array}{llllll}\text { Message } \\
\text { Agreement with the message }\end{array}$ & $4.18(4.19)$ & 0.16 & & $4.62(4.59)$ & 0.15 \\
Clarity & $5.34(5.35)$ & 0.15 & & $5.25(5.24)$ & 0.14 \\
& & & & \\
Source & & & & \\
Likeable/nice Trustworthiness & $4.02(4.05)$ & 0.15 & & $4.49(4.46)$ & 0.18 \\
Competency & $3.35(3.38)$ & 0.18 & & $4.02(3.99)$ & 0.18 \\
& $3.73(3.75)$ & 0.19 & & $4.03(4.01)$ & 0.19 \\
Behavioral intentions & & & & \\
Drink more tap water & & & & \\
Not buying bottled water & $2.82(2.91)$ & 0.24 & & $3.74(3.69)$ & 0.24 \\
& $1.73(1.80)$ & 0.20 & $2.70(2.64)$ & 0.20 \\
\hline
\end{tabular}

Note. $M_{A d j}=$ means adjusted for the covariate. 


\section{Discussion}

Our study explored the possibility of using a goal priming technique to enhance persuasion by priming goals related to features typically associated with source effects. Specifically, our aim was to use goal priming to directly influence the trust in the message and its source. Results indicated that participants primed with the goal of trusting not only evaluated more positively the message and its source, but also expressed more behavioral intentions in line with the message. Results extend Strahan et al.'s (2002) findings, which indicated that a message could be perceived as more persuasive even when it does not correspond to an active motive or need. In our case, activating the goal "to trust" facilitated the acceptance and enhanced the persuasiveness of the subsequently displayed message. Results are also in line with the idea that the goal "to trust" is a general goal that can influence information processing and behavioral intentions, extending Albarracin et al.'s (2008) findings.

In sum, our study demonstrated that subliminally priming a goal targeting the credibility dimension influences perception of the message and of its source as well as its consequences in terms of behavioral intentions. Potential practical implications of these findings are numerous. On the bright side, results could be used to develop pro-cedures helping to promote public health campaigns (quit smoking, safe driving). As a darker alternative, advertisers could be tempted to use them to persuade consumers to try or buy a product they weren't previously interested in. Even if many countries forbid the use of subliminal advertising, it does not mean that nonconscious influences and nonconscious goal pursuit do not occur in a natural setting or that goal priming cannot be used to enhance the per-suasiveness of a message or people's receptivity to a message. Indeed, incidental exposure (i.e., products or brands unobtrusively presented in a setting) is rather close of subliminal priming in terms of effects (Berger \& Fitzsimons, 2008). This kind of exposure is frequently manipulated in natural settings (e.g., in TV shows, websites, video games, or more generally in supermarkets and crowded places) and could allow goal priming such as the one we used to occur and operate.

Future research should address other issues that our current findings did not resolve. First, underlying processes need to be refined. How does motivation "to trust" operate? Does it work as a filter, leading people to focus only on positive/pros arguments in the mes-sage? Does it "lower people's shields" and if so, under what circumstances, if any? Moreover, motivation may be one option, but not the only possible explanation. Indeed, as our experiment did not measured motivation, we cannot exclude a non-motivational explanation for this effect. For instance, it could be that trust primes cause people to perceive the source as more trustworthy, which drives the effects. A future study will have to decide between these two possibilities. Second, priming has to be studied in combination with other classic source effects' features of persuasion, such as message framing (e.g., Kahneman \& Tversky, 1979). For example, goal priming could be associated with a goal framing manipulation (Levin, Schneider, \& Gaeth, 1998) to influence implicit goals of "obtaining the positive consequence (i.e., positive framing)" or "avoiding the negative consequence (i.e., negative framing)". In particular, priming a goal congruent with the goal stressed in the goal-framing message should influence the evaluation of the message and, consequently, enhance its persuasiveness. Finally, we used a unilateral message concerning a quite consensual topic (drinking tap water). It might be interesting to extend this study to other types of messages, including counter attitudinal, political, or even religious.

\section{References}

Albarracin, D., Handley, I., Noguchi, K., McCulloch, K., Li, H., Leeper, J., et al. (2008). Increasing and decreasing motor and cognitive output: A model of general action and inaction goals. Journal of Personality and Social Psychology, 95, 510-523. Baldwin, M. W., Carrel, S. E., \& Lopez, D. F. (1990). Priming relationship schemas: My advisor and my pope are watching me from the back of my mind. Journal of Experimental Social Psychology, 26, 435-454.

Bargh, J. A., Gollwitzer, P. M., Lee-Chai, A., Barndollar, K., \& Trötschel, R. (2001). The automated will: Nonconscious activation and pursuit of behavioral goals. Journal of Personality and Social Psychology, 81, 1014-1027.

Bargh, J. A., \& Pietromonaco, P. (1982). Automatic information processing and social perception: The influence of trait information presented outside of conscious awareness on impression formation. Journal of Personality and Social Psychology, 43 , 437-449.

Berger, J., \& Fitzsimons, G. (2008). Dogs on the street, pumas on your feet: How cues in the environment influence product evaluation and choice. Journal of Marketing

Research, 45, 1-14.

Brasel, S. A., \& Gips, J. (2011). Red Bull "Gives You Wings" for better and worse: a double-edged impact of brand exposure on consumer performance. Journal of Consumer Psychology, 21, 57-64.

Channouf, A. (2000). Subliminal exposure to facial expressions of emotion and evaluative judgments of advertising messages. European Review of Applied Psychology, 50, 19-23.

Chartrand, T. L., \& Bargh, J. A. (1996). Automatic activation of impression formation and memorization goals: Nonconscious goal priming reproduces effects of explicit task instructions. Journal of Personality and Social Psychology, 71, 464-478.

Cooper, J., \& Cooper, G. (2002). Subliminal motivation: A story revisited. Journal of Applied Social Psychology, 32, 2213-2227.

Custers, R., \& Aarts, H. (2010). The unconscious will: How the pursuit of goals operates outside of conscious awareness. Science, 329, 47-50.

Dijksterhuis, A., Wegner, D. M., \& Aarts, H. (2001). Unpublished datad set. (Referred to in Dijksterhuis, Aarts, \& Smith, 2005).

Dijksterhuis, A., Aarts, H., \& Smith, P. K. (2005). The power of the subliminal: Subliminal perception and possible applications. In R. Hassin, J. Uleman, \& J. A. Bargh (Eds.), The new unconscious (pp. 77-106). New York, NY: Oxford University Press.

Fiske, S. T., \& Taylor, S. E. (2008). Social cognition. New York: McGraw-Hill. Kahneman, D., \& Tversky, A. (1979). On the interpretation of intuitive probability: A reply to Jonathan Cohen. Cognition, 7, 409-411.

Karremans, J. C., Stroebe, W., \& Claus, J. (2006). Beyond Vicary's fantasies: The impact of subliminal priming and brand choice. Journal of Experimental Social Psychology, 42 792-798.

Levin, I. P., Schneider, S. L., \& Gaeth, G. J. (1998). All frames are not created equal: A typology and critical analysis of framing effects. Organizational Behavior and Human Decision Processes, 76, 149-188.

Muir, M. (1993). Subliminal [recorded by M. Dodson \& M. Muir]. On Still cyco after all these years [CD]. New York: Epic.

Petty, R. E., \& Wegener, D. T. (1998). Attitude change: Multiple roles for persuasion variables. In D. T. Gilbert, S. T. Fiske, \& G. Lindzey (Eds.), (4e ed). The handbook of social psychology, Vol. 1. (pp. 323-390)Boston: McGraw-Hill.

Strahan, E. J., Spencer, S. J. \& Zanna, M. P. (2002). Subliminal priming and persuasion: Striking while the iron is hot. Journal of Experimental Social Psychology, 38, 556-568.

Zajonc, R. B. (1980). Feeling and thinking: Preferences need no inferences. American Psychologist, 35, 151-175. 